\title{
Isolation, Identification and Optimization of Crude Oil Degrading Micromycetes for Biosynthesis of Poly Unsaturated Fatty Acids
}

\author{
Mehdi Ghasemi", Yemen Atakishiyeva \\ Institute of microbiology, Azerbaijan National Academy of Sciences, Baku, Azerbaijan
}

Email address:

mehdi_aidin@yahoo.com (M. Ghasemi), y.atakishiyeva@mail.ru (Y. Atakishiyeva)

To cite this article:

Mehdi Ghasemi, Yemen Atakishiyeva. Isolation, Identification and Optimization of Crude Oil Degrading Micromycetes for Biosynthesis of Poly Unsaturated Fatty Acids. American Journal of Life Sciences. Vol. 3, No. 3, 2015, pp. 147-157. doi: 10.11648/j.ajls.20150303.14

\begin{abstract}
Poly unsaturated fatty acids (PUFAs) participate in activities of all organisms from energy source to structural components. Disruption of metabolism results in diseases like atherosclerosis and obesity. In this work, optimal conditions to production of arachidonic, eicosapentaenoic and gamma- linolenic acids has been conducted in the oil degrading fungi-Cephalosporium humicola IE, Mucor globosus 11 and Pythium irregulare LX isolated from soils in Absheron peninsula, Azerbaijan. The fermentation process carried out at physicochemical conditions, carbon and nitrogen sources, temperature, $\mathrm{pH}$, rate of inoculum, enzyme activity, exogenous fat and phosphate; as well as the stressful situations. Growth in crude oil as optimal carbon source showed that suitable nitrogen was peptone for lipid biosynthesis. In stable temperature the optimal lipid productionoccurred at $28^{\circ} \mathrm{C}$, whereas in "temperature shifting technique", greater yields occurred at $28^{\circ} \mathrm{C}$ for 5 days followed by at $15^{\circ} \mathrm{C}$ for 2 days. $\mathrm{C} / \mathrm{N}$ ratio ranged from 4 to 64 and the optimal medium for production was composed of $2.0 \%$ glucose and $0.25 \%$ yeast extract, with addition of $0.1 \% \mathrm{KH}_{2} \mathrm{PO}_{4}$ at neutral $\mathrm{pH}$ with $3 \%$ inoculum. Although the activities of the enzymes varied among the fungi, but the developmental profiles for all enzymes were practically similar. Additive fat and phosphate accelerated growth and enhanced PUFA production. Data showed that the procedure of adaptation of fungi motivated the increase of the rate of membrane phospholipids with a high quantity of PUFAs. This research is considered to be object of PUFA production as food supplements.
\end{abstract}

Keywords: Ascomycetes, Zygomycetes, Oomycetes, Lipid, SCO, PUFA, Crude Oil, Omega

\section{Introduction}

Poly unsaturated fatty acids (PUFA), which have 18 and up carbon and two or more double bound in their structure, participate in the normal activities of all organisms, from prokaryotes to multicellular eukaryotes. These compounds play a vital role in body's energy source as well as in structural components of in mammalian cell. Not surprisingly, disruption of lipids and fatty acids metabolism in organisms lead to many diseases in skin, nervous system, immune system, inflammation, cardiovascular, atherosclerosis, endocrine system, kidneys, respiratory and reproductive systems and obesity (1).

Currently, the elderly as well as children are in high demand for unsaturated fatty acids, as nutritional supplements. Unsaturated fatty acids, especially the long-chain and high unsaturated fatty acids are advised to add to diet in order to improvement of coronary heart problems, retinal eye and brain functions. Eicosapentaenoic acid (EPA; 20:5n-3; omega 3 or $\omega-3)$, gamma- linolenic acid (GLA; 18:3n-6; omega 6 or $\omega-6$ ) and arachidonic acid (ARA; 20:4n-6; omega 6 or $\omega-6$ ) are not synthesized in the human body and must be added to food.Synthesis of PUFA goes by carbon chain elongation and desaturation. PUFA metabolic phases carry out with the $\Delta-6$ desaturase, $\Delta-5$ desaturase and elongase enzymes. Mammals are not able to synthesis long-chain PUFA due to the lack of compatible enzymes; therefore they are obliged to accept them with food (2).

Natural sources of PUFA are plants, animals and microorganisms. But, throughout history, people used only the nutrition oils of plants and animals such as butter and lard. Microbial oil or "single-cell oils"(SCO) is relatively new concept, and has been proposed for the first time in the 20th century (3). However, the price of SCO is rather high than plant and animal oils so that obtaining of oil by microbiological ways 
are less likely in industrial scales, even in the near future $(4,5)$. In this regard, recent attempts were directed only by biosynthesis of the high value poly unsaturated fatty acids, as food supplements, which plants are not able to produce them (68).

Microorganisms that synthesize the PUFA are fungi, bacteria and seaweeds (9-12). However, the bacteria are not suitable as PUFA producer, because do not contain high amounts of triacylglycerol and they have an unusual fatty acids and lipids, which the other systems do not deal with them. Oleaginous micromycetes are economically feasible sources for the production of PUFA. Fungi may be an alternative to fish oil due to the high amount of PUFA. In addition to, there is not only mixture of unsaturated fatty acids in the lipid composition of micromycetes, but it has also unique PUFA (13). At the present time, we can say that microorganisms are not utilized to production of PUFA. However, there are number of serious reasons for continuing research. First, microorganisms, which product the high amount of PUFA, should be selected, second, the microbial stability of lipids oxidation is higher than fish oil (12), third, PUFA can be produced from cheaper raw materials, in addition, knowledge gained from genetics and biochemistry of biosynthesis of PUFA is useful for new production systems or products. Thus, the study of biosynthesis, metabolism and regulation of lipid in fungi, not only has theoretical interest but is also very important for modern medicine, veterinary and agriculture.

The purposes of this work were the selection of the fungi species to biosynthesis of PUFA, determination of the conditions for obtaining the required high amounts of product, as well as study the effect of stress conditions in the synthesis of fatty acids and lipogenesis.

\section{Materials and Methods}

\subsection{Screening and Isolation of Oleaginous Fungi from Oil-Contaminated Soil}

The screening of fungi carried out in Microorganism Culture Collection of Institute of Microbiology at Azerbaijan National Academy of Sciences, which already were isolated from oil-contaminated soils near Baku, Azerbaijan. The species of class Zygomycetes and Ascomycetes, which have the ability to synthesize the C-18 fatty acids, were cultured by deep cultivation method in rotary incubator shaker $220 \mathrm{rpm}(3$, 14- 24). The broth medium for fungi was composed of $3 \%$ glucose, $0.2 \%$ sodium nitrate, $0.1 \%$ potassium dihydrogen phosphate, $0.05 \%$ potassium chloride, $0.05 \%$ magnesium sulphate-heptahydrate, and $0.001 \%$ iron (II) sulphate-heptahydrate ( $\mathrm{pH}$ 5.5). Culture flasks $(500 \mathrm{ml})$ containing $200 \mathrm{ml}$ of the medium were inoculated with vegetative mycelium and cultivated for 5-10 days at $28^{\circ} \mathrm{C}$. Flasks were periodically removed from the incubator and mycelia were collected by centrifugation at $22000 \mathrm{rpm}$ for 20 minutes and washed once with distilled water. Lipids were extracted and analyzed by HPLC to determine of fatty acids compositions $(25,26)$.
Moreover, micromycetes in contaminated soils are considered to be object of the experiment. For this purpose, gray-brown oil-contaminated topsoil samples, from Absheron, Azerbaijan, after dismissal $(1.5-2 \mathrm{~cm})$ were collected by sterile trowel and thrown into jars. General features of the soil has been characterized as follows: the sample was not taken from the area of flora, poor soil structure, moisture $26.4 \%$, the amount of humus $1-2 \%$, weakly alkaline, the oil amount was $2.8 \%$ in dry weight soil. Agar- agar $2 \%$ and Capek-Dock medium used for primary cultivation of fungi. The composition of Capek-Dock medium was (g/l): sucrose - 30, $\mathrm{NaNO}_{3}-2, \mathrm{~K}_{2} \mathrm{HPO}_{4}-1, \mathrm{MgSO}_{4} \times 7 \mathrm{H}_{2} \mathrm{O}-0.5, \mathrm{KCl}-0.5$; $\mathrm{FeSO}_{4} \times 7 \mathrm{H}_{2} \mathrm{O}-0.01$, agar - 20, $\mathrm{pH}-5.0-5.5$, streptomycin $20 \mu \mathrm{g}$. Antibiotic was sterilized through membrane filters and added to medium before culturing, in order to prevent of bacterial contamination. In all cases, mediums $\mathrm{pH}$ reduced to 5.0- 6.0 by $\mathrm{HCl} 10 \%$ or $\mathrm{NaHCO}_{3}(27)$.

In isolation stage, first $60-100 \mathrm{~g}$ soil samples were cleaned from small stones and so on, screened in $2.5 \mathrm{~mm}$ perforated sieve, homogenized, wetted until the formation of pasta shape and cultured in correct places by loop (4 point in each Petri dish) and then incubated aerobically in the solid medium, as well as it was done in incubator shaker with $220 \mathrm{rpm}$ in the broth medium at $5-10^{\circ} \mathrm{C}$ for $10-30$ days. The fungi were classified under the microscope through morphology characteristics $(28,29)$. Fungi were maintained in two ways, suspensions of spores and slant tube methods in the Capek-Dock medium $(30,31)$.

The initial identification of oleaginous fungi was done by Black Sudan B staining protocol, consequently the fat droplets was observed in the blue or grayish color of the cells under microscope. As a result, 24 strains were collected. The biomass separated from $100 \mathrm{ml}$ cultures by centrifugation $6000 \mathrm{rpm}$ for 15 minutes, washed twice with distilled water, and then filtered by Whatman No. 1 filter paper; biomass weight was stable at $65^{\circ} \mathrm{C}$. The samples dried up to determine of oil-polluted rate of soil; the oil was extracted by Soxhlet extractor by using petroleum or hexane (32). The selected micromycetes were cultured in the solid Capek-Dock medium containing different concentrations of aspirin $(0.25,0.5,0.75$ and $1.0 \mathrm{~g} / \mathrm{l})$ at $25^{\circ} \mathrm{C}$ and at last diameter of the grown colonies were measured every 12 hours (33).

\subsection{The rate and Qualitative Analysis of Lipids}

The extraction of lipids was used by the method of Folch and Bligh -Dayer $(34,35)$. The lyophilized biomass were agitated with $4.0 \mathrm{ml}$ distilled water $+5.0 \mathrm{ml}$ chloroform +10 $\mathrm{ml}$ methanol in tube for 5 minutes, and then were kept shaking 3-4 hours at room temperature. Extraction was continued for 30 minutes, after adding $5.0 \mathrm{ml}$ chloroform $+5.0 \mathrm{ml}$ distilled water, filtered and poured into separator funnel. Filters were washed by $12.5 \mathrm{ml}$ chloroform, and united at last. After stratification methyl alcohol + water layer were divided in separator funnel completely, the chloroform layer was brought to a constant weight, poured in a pear-shaped vacuum flask and evaporated in vacuum. The total lipid found in biomass as follows: 


$$
\mathrm{TL}=\frac{\mathrm{m} 2-\mathrm{m} 1}{\mathrm{a}} 100
$$

Where, $\mathrm{TL}=$ the total lipids $(\%), \mathrm{ml}=$ the empty weight of flask $(\mathrm{g}), \mathrm{m} 2=$ the weight of flask with biomass $(\mathrm{g}), \mathrm{a}=$ the weight of biomass $(\mathrm{g})$

Neutral lipids were separated from polar lipids by precipitation with cold acetone. For dissolving during the separation of fractions, a portion of the lipid solution $(100 \mathrm{mg})$ was carried into $15 \mathrm{ml}$ centrifuge test-tubes. The solution was evaporated up to $0.2-0.3 \mathrm{ml}$ in nitrogen stream at $30^{\circ} \mathrm{C}, 5 \mathrm{ml}$ acetone and $0.1 \mathrm{ml}$ of $\mathrm{MgCl}_{2} \times 6 \mathrm{H}_{2} \mathrm{O}$ in methanol solution $10 \%$ was added, mixed and cooled in ice water bath for an hour. The suspension was precipitated in centrifuge at 2500 rpm for 3-5 minutes; supernatant was cleared out by Pasteurpipette. Sediment was washed and made suspension in $1 \mathrm{ml}$ of cold acetone; the suspension was cooled in ice water bath and precipitated. Washing was repeated twice, and precipitated phospholipids were dried in nitrogen stream on $\mathrm{KOH}$ in the vacuum desiccators. The dried sediment is weighted and dissolved in determined volume of chloroform. The combined acetone supernatant is evaporated; the neutral lipids are weighted and dissolved in determined volume of chloroform. The dry weight is determined by a portion of the chloroform solution. Both non-acetone-soluble and acetone-soluble fractions were analyzed by silica acid impregnated paper chromatography. Fractionation of polar lipids have been carried out in the chloroform/methanol/water $(65: 25: 4$, by vol) and fractionation of neutral lipids have been carried out in the hexane/diethyl ether/acetic acid (85:25:4, by vol) systems by thin-layer chromatography. The transfer of lipids on preparation boards were done by drops with petroleum ether or benzene (neutral lipid), chloroform, or chloroform/methanol (9:1, by vol, polar lipid) $5-10.0 \%$ solution. The chloroform - methanol - water $(65: 25: 4)$ were carried out to obtain the fractions of polar lipids, and the hexane/diethyl ether/acetic acid (85:25:4, by vol) solvents systems with thin-layer chromatography method were carried out for neutral lipids. For this purpose, silufol boards were used. Separated compounds were identified by the standard lipid preparation, as well as these systems have been assessed by Rf. The amount of lipid components was determined by densitometry. The fatty acids composition of lipids was determined by HPLC. For this purpose, the mixture of methylated fatty acids was divided by methanolic acid into UV detector $(\lambda=250 \mathrm{~nm})$ KOBO marked (Czech Republic) the liquid chromatography. The structure of fatty acids was also determined by Mass-spectrum analysis $(34,35)$.

The number of double bound was calculated by determination of "the number of iodine" protocol: first ethanol was added over lipid sample in $50 \mathrm{ml}$ flasks, and then $12.5 \mathrm{ml}$ of $0.1 \mathrm{~N}$ ethanol solution of iodine was added and mixed. A control flask only had $25.0 \mathrm{ml}$ ethanol and the same amount of ethanol solution of iodine. $100 \mathrm{ml}$ distilled water was added to both of flasks, then strapped, shaken, and after 5 minutes titration with the thiosulfate solution $0.1 \mathrm{~N}$ was continued until appearance of the yellow color. After, $1 \mathrm{ml}$ of starch solution was added, titration lasted until disappear of the blue color. Finally the iodine number was calculated as follows:

$$
\mathrm{IN}=(\mathrm{V} 1-\mathrm{V} 2) \times 0.0127 / \mathrm{a}
$$

IN - measured with the amount of iodine combined with $100 \mathrm{~g}$ lipid (g), V1 - the volume of thiosulfate solution $0.1 \mathrm{~N}$ used in titration in control variant $(\mathrm{ml}), \mathrm{V} 2$ - the volume of thiosulfate solution $0.1 \mathrm{~N}$ used in titration in tested variant (ml), 0.0127 - the titration of thiosulfate according to iodine, a - lipid sample weight (g)(36).

\subsection{The Selection of Physicochemical Factors of Medium}

The effects of changes in the initial $\mathrm{pH}(4-8)$ in the medium, as well as temperature $\left(15,21\right.$ and $\left.28^{\circ} \mathrm{C}\right)$ were studied on amount of biomass, lipid and PUFA compositions. In "Temperature Shifting Technique" first fungi were cultured for 3,4 or 5 days at $28{ }^{\circ} \mathrm{C}$, after incubation temperature was reduced to $15{ }^{\circ} \mathrm{C}$ and the biomass was collected in 7 th days. The effect of different concentrations of inoculum $(0.5,1.0$, 2.0,3.0, 4.0 and $5.0 \%, 1.5 \times 10^{6}$ spore per $\mathrm{ml}$ ) were studied on biomass, lipid and PUFA synthesis after 6 days at $28{ }^{\circ} \mathrm{C}$.

As a source of nitrogen $\mathrm{CO}\left(\mathrm{NH}_{2}\right)_{2}, \mathrm{NaNCO}_{3}, \mathrm{NH}_{4} \mathrm{Cl}$, $\mathrm{NH}_{4} \mathrm{NO}_{3}$ and yeast extract was used in Capek-Dock medium. The amount of nitrogen compounds in accordance with medium $(0.33 \mathrm{~g}$ of nitrogen per liter of medium) was $0.7,1.95$, $1.23,0.92$ and $0.33 \mathrm{~g}$, respectively. Initial $\mathrm{pH}$ was 6.0-6.2 (If necessary, the $\mathrm{pH}$ was increased by $\mathrm{KOH} 40 \%$ ). Yeast extract and glucose as a source of nitrogen and carbon with a ratio of $20: 1,34: 1,50: 1,75: 1,100: 1$, respectively, was used to study the effect of $\mathrm{C} / \mathrm{N}$. Cultures were grown in medium containing glucose, yeast extract and $0.1 \% \mathrm{KH}_{2} \mathrm{PO}_{4}$ at $28{ }^{\circ} \mathrm{C}$ for 5 days aerobically. In the next experiments $1.0 \%$ palmitic, stearic, and miristic acids, as well as flax and cotton oils were added to the basic substrate crude oil (1.0\%), and finally were analyzed by chromatography. The effects of exogenous phosphorus composition $\left(\mathrm{K}_{2} \mathrm{HPO}_{4}\right)$ were studied on cell lipids and their fatty acids structure at different concentrations $(0.5,1.0,2.0$ and $5.0 \mathrm{~g} / \mathrm{l})$ at $28{ }^{\circ} \mathrm{C}-30{ }^{\circ} \mathrm{C}$ for 7 days, aerobically. The amount of phosphorus in the broth medium with crude oil was 89.0, 178.0, 356.0 and $890.0 \mathrm{mg}$ per liter.

\subsection{Stress Situation}

Crude oil with 1.0, 2.0, 3.0, 5.0 and $10.0 \%$ concentrations were added to broth medium containing glucose. Cultivation was 5 days.

All of the above was repeated three times. Data were analyzed using ANOVA in SPSS software.

\section{Results}

The results of screening of fungi of Culture Collection have presented in Table 1. In accordance with the analysis, the lipid compositions of $M$. globosus 11 and $C$. humicola IE have not contained eicosane, but a sufficient amount of C18:3 were synthesized in crude oil substrates and this topic was caused to select of them as next object of the experiments. In the next 
experiment the isolation of lipogenous fungi from soil showed sensitivity of four isolated fungi to aspirin among 24 isolated strains after 5 days. The growth and lipid accumulation in $C$. humicola IE, M. globosus 11 and P. irregulare $L X$ selected as the synthesis of PUFA in the substrates glucose and crude oil, which were used in medium, have determined in Figure 1. The comparative analysis of lipid fractions composition indicated that all three fungi contained neutral lipid, triacylglycerol, diacylglycerol, monoacylglycerols, free fatty acids, polar lipids, free sterols, sterols esters, cardiolipin, glycolipid, phosphatidylserine, phosphatidylethanolamine, phosphatidylcholine, phosphatidic acid and some factions have not been identified. The activity of multienzyme complex of fatty acid synthesis system had a certain position in studying (Table 2). The initial $\mathrm{pH}$ in the medium with glucose to product of maximum amounts of biomass was 6.0, 0.6 and 0.7 in C. humicola, $M$. globosus and $P$. irregulare, but in medium withcrude oil substrates was lower, $0.5,0.5$ and 0.6 , respectively. But, the optimal $\mathrm{pH}$ to biosynthesis of PUFA was $0.7,0.7$ and 0.8 , respectively. The growth curve of $C$. humicola IE,M. Globosus 11, and P. irregulare $L X$ in medium with glucose were formed within 4,5 and 5 days at $28^{\circ} \mathrm{C}, 6,6$ and 7 days at $21{ }^{\circ} \mathrm{C}$ and 9,7 and 11 days at $15{ }^{\circ} \mathrm{C}$, respectively. Consequently to optimize of lipid production the cultures were grown for 3,4 or/and 5 days at $28{ }^{\circ} \mathrm{C}$, and followed by the

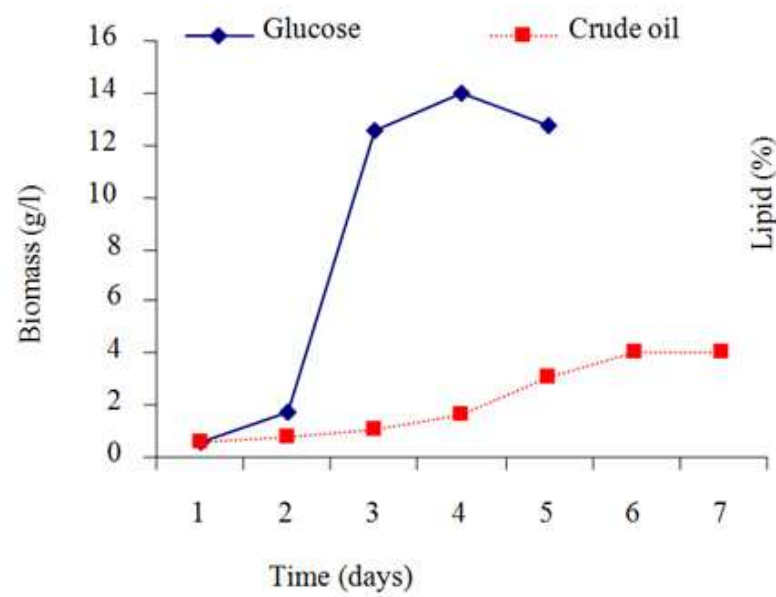

incubation temperature was reduced to $15^{\circ} \mathrm{C}$ and biomass accumulated of 7 days. The data in Table 3 showed that effect of different nitrogen sources on biomass, lipids and PUFA. The effect of carbon-nitrogen ratio on the biomass, lipid and PUFA has been shown in Table 4. The sixteen different mediums combination were used to study the effect of $\mathrm{C} / \mathrm{N}$ on productivity of ARA and EPA in biomass (Table 5). Results of using exogenous fat and fatty acids as an essential or additional source of carbon in medium have been presented in Table 6 . The graphics of vegetable oil and fatty acids showed a positive impact on the growth and lipid production of microorganisms (Figure 2). The results showed that the intensity of lipogenesis depended on the quantity of additive phosphate to the medium (Table 7). The results presented in table 8 showed that more effect of phosphate concentration on palmitic, linoleic and linolenic acids of the lipid composition was in M. globosus 11. The effect of phosphate concentration was different in the other two fungi. Adaptation of microorganisms to the different stress situation was important due to the changes of lipid and fatty acid composition. The results of growth, lipogenesis, polar lipids, neutral lipids and unsaturated fatty acids especially with increase in the proportion of phospholipids of fungi, in fact the increase in degree of unsaturation; in different concentrations of crude oil were added to medium confirmed this fact, despite the delay in growth of them.

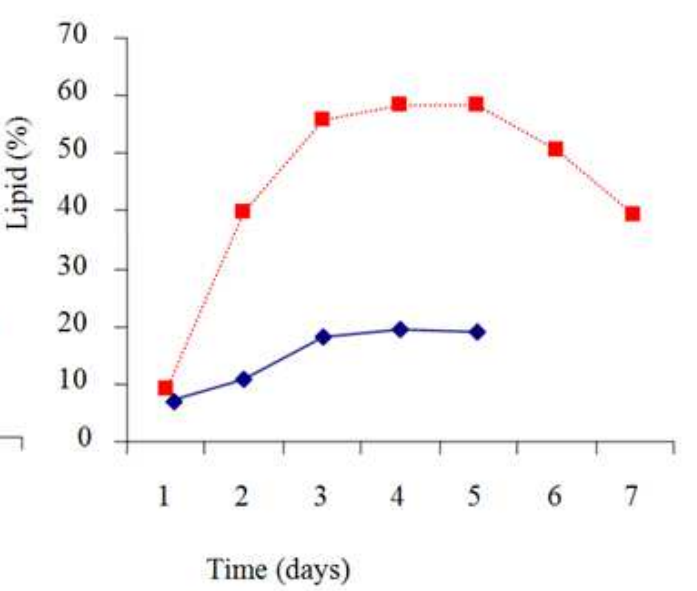

A

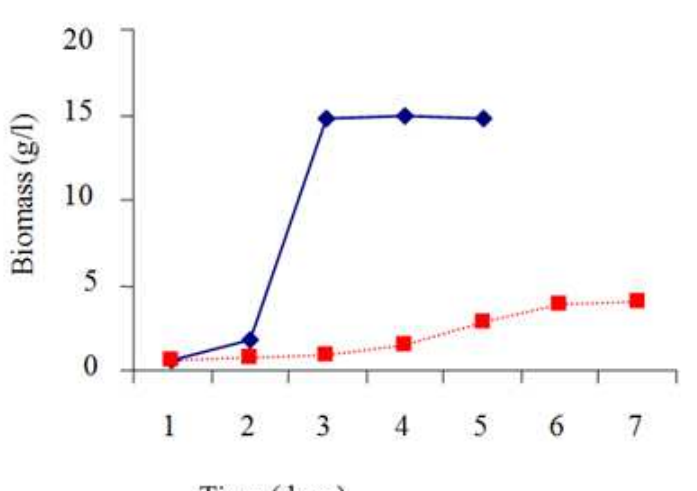

Time (days)

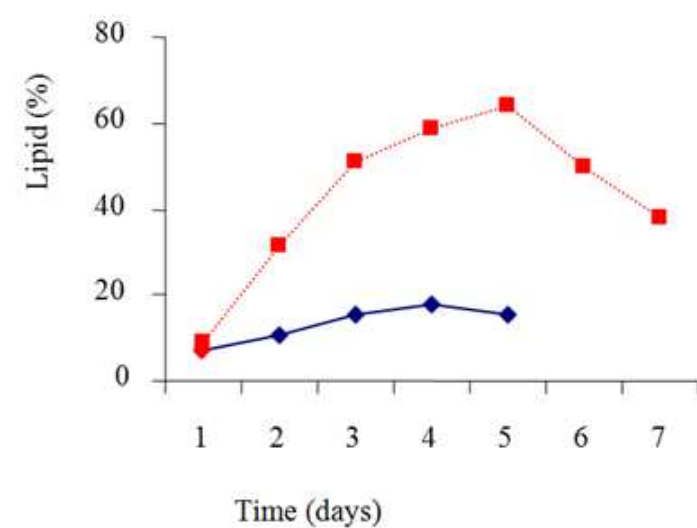

Time (days) 

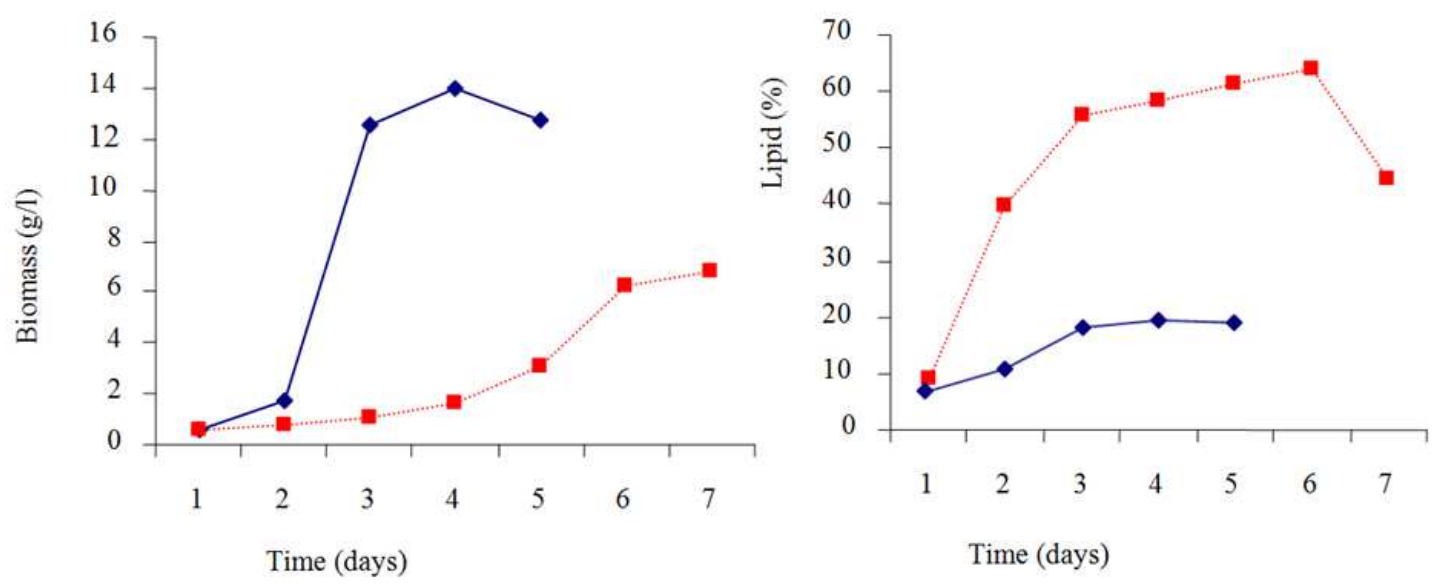

$\mathrm{C}$

Figure 1. Lipid accumulation in C. Humicola IE (A), M. Globosus 11 (B) and P. irregulare LX (C) grown on glucose and crude oil.
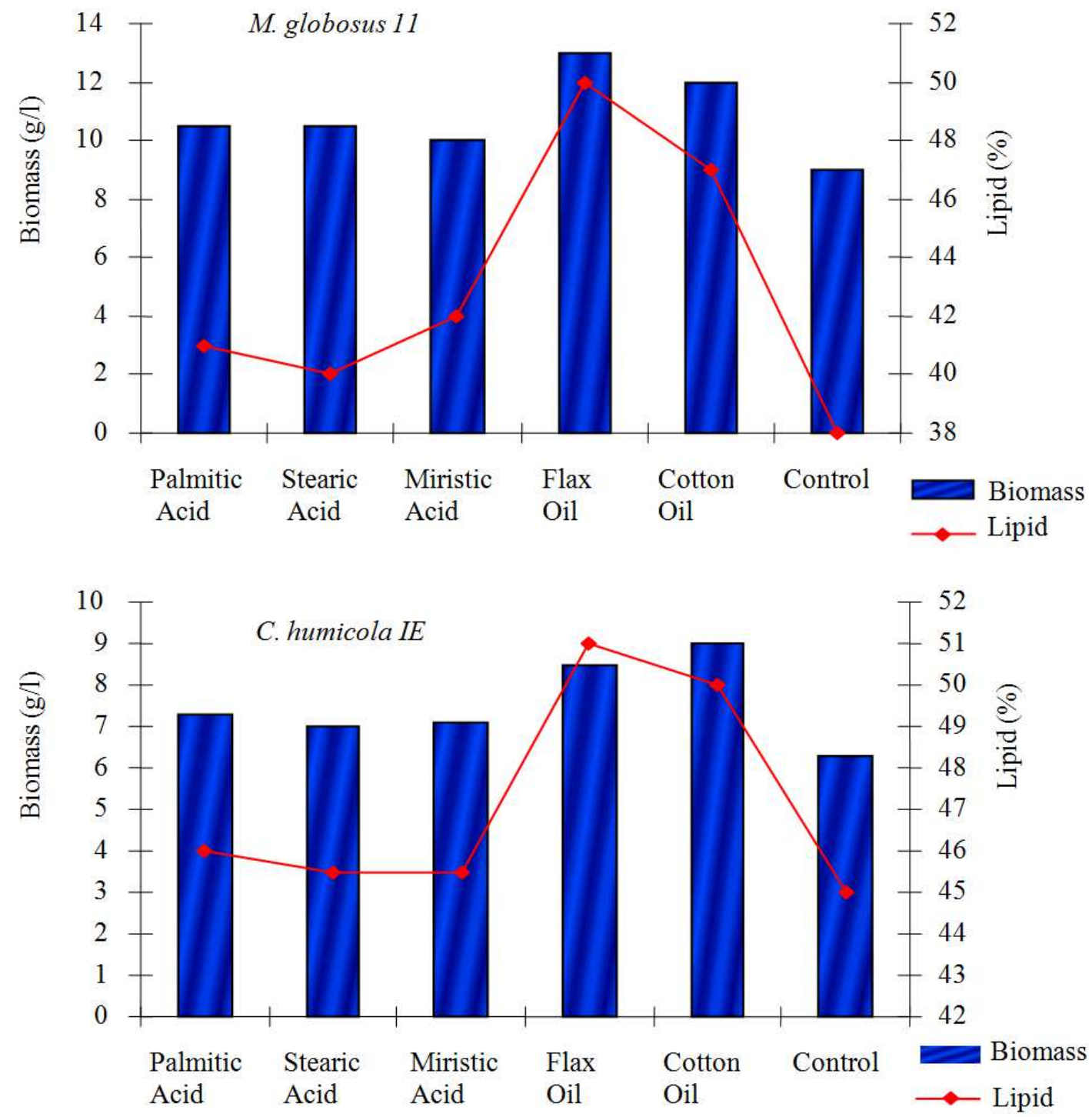


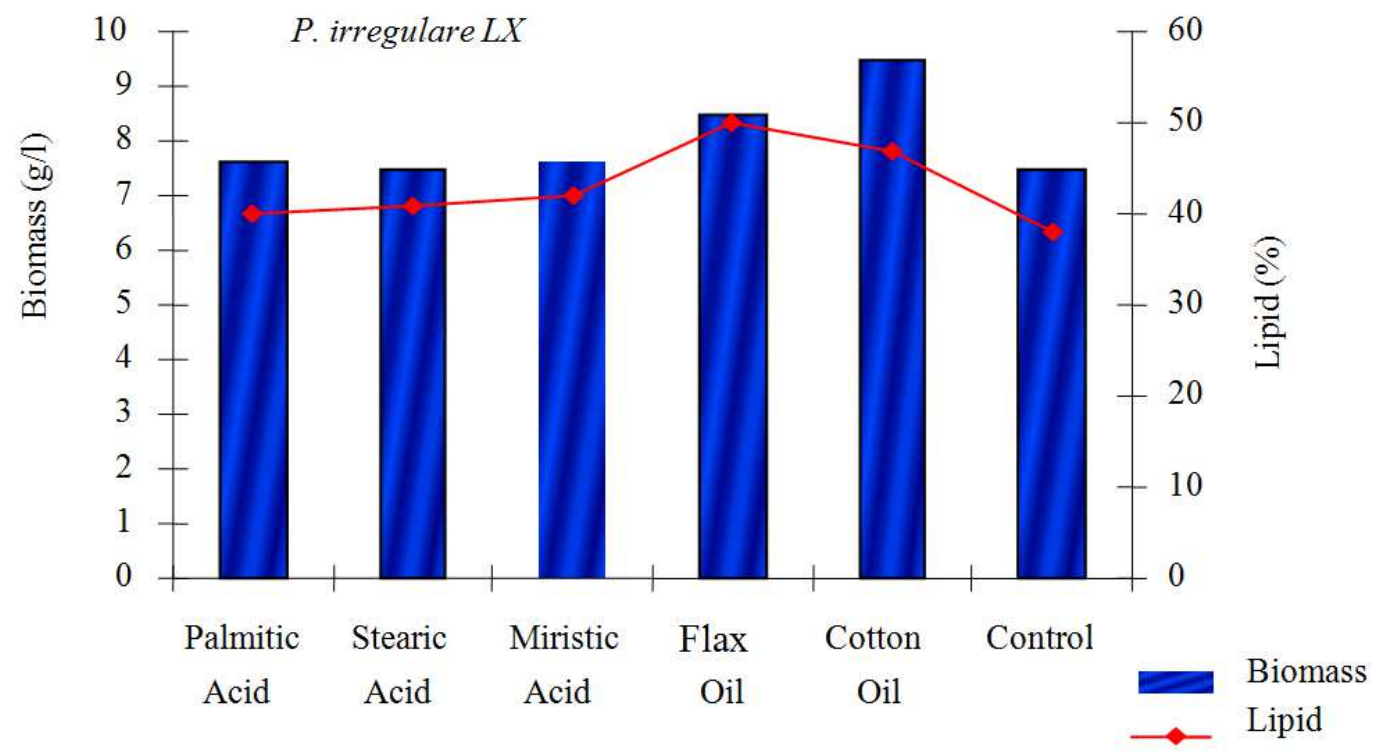

Figure 2. The difference in growth rates and lipid production of fungi in the presence of different fatty acids and vegetable oils.

Table 1. The rate of lipid and the composition of fatty acids in Azerbaijan National Academy of Sciences collection cultures of micromycetes.

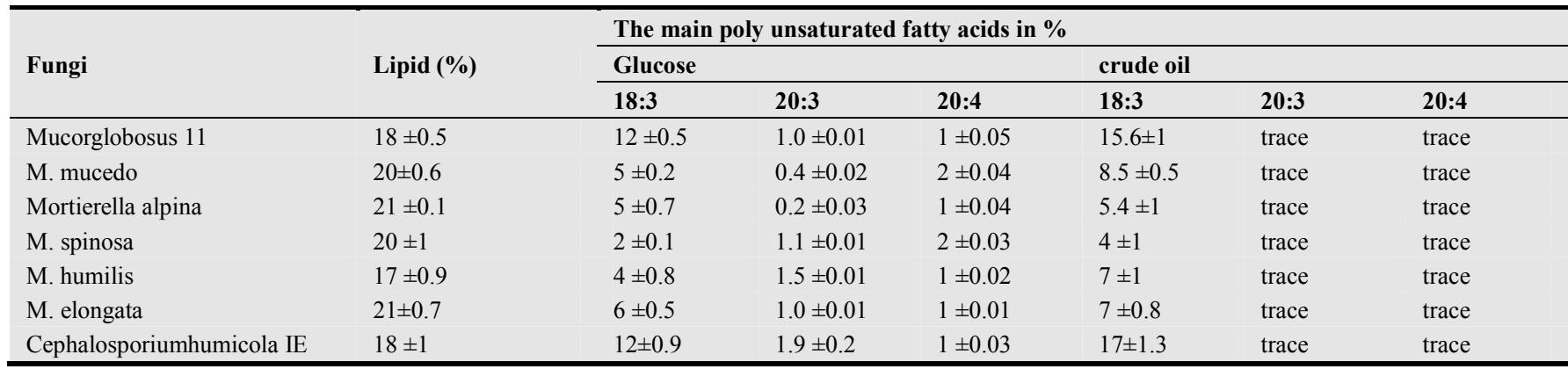

Table 2.The enzymes activities (nmol/min/mg protein) in fungi grown on glucose and crude oil.

\begin{tabular}{|c|c|c|c|c|c|c|}
\hline \multirow{2}{*}{ enzyme } & \multicolumn{2}{|c|}{ C. humicola IE } & \multicolumn{2}{|c|}{ M. globosus 11} & \multicolumn{2}{|c|}{ P. irregulare $L X$} \\
\hline & glucose & crude oil & glucose & crude oil & glucose & crude oil \\
\hline Malic enzyme & $36 \pm 1.2$ & $18 \pm 1.3$ & $22 \pm 2.1$ & $11 \pm 1.2$ & $24 \pm 2.4$ & $13 \pm 1.1$ \\
\hline Glucose-6-phosphate dehydrogenase & $1100 \pm 2.3$ & $200 \pm 1.2$ & $980 \pm 2.2$ & $120 \pm 1.4$ & $1060 \pm 1.5$ & $17 \pm 0.9$ \\
\hline Fatty acid synthase & $33 \pm 0.8$ & $40 \pm 1.4$ & $23 \pm 1.8$ & $23 \pm 1.3$ & $27 \pm 1.6$ & $33 \pm 0.7$ \\
\hline Acetyl-CoA carboxylase & $2.5 \pm 0.4$ & $4.8 \pm 2.3$ & $3.1 \pm 0.9$ & $5.3 \pm 1.9$ & $6.5 \pm 0.1$ & $5.9 \pm 1.4$ \\
\hline Isocitratelysase & - & $58 \pm 1.6$ & $5 \pm 1.1$ & $40 \pm 1.6$ & $7 \pm 0.5$ & $45 \pm 1.4$ \\
\hline Carnitin acetyl transferase & $34 \pm 1.3$ & $351 \pm 2.1$ & $22 \pm 2.1$ & $230 \pm 2.1$ & $29 \pm 0.7$ & $310 \pm 1.8$ \\
\hline Pyruvate kinase & $820 \pm 2.6$ & $160 \pm 2.1$ & $600 \pm 1.7$ & $67 \pm 2.6$ & $703 \pm 0.9$ & $89 \pm 2.1$ \\
\hline
\end{tabular}

Table 3. The rate of biomass, lipid compositions and poly unsaturated fatty acids in different $N$ sources.

\begin{tabular}{|c|c|c|c|c|c|c|}
\hline & $\mathrm{CO}\left(\mathrm{NH}_{2}\right)_{2}$ & $\mathrm{NaNO}_{3}$ & $\mathrm{NH}_{4} \mathrm{Cl}$ & $\mathrm{NH}_{4} \mathrm{NO}_{3}$ & Peptone & Yeast extract \\
\hline \multicolumn{7}{|l|}{ Glucose } \\
\hline M. globosus 11 & & & & & & \\
\hline Biomass, g/1 & $13.7 \pm 0.6$ & $14.0 \pm 0.5$ & $11.3 \pm 0.5$ & $10.0 \pm 0.6$ & $13.1 \pm 0.6$ & $16.1 \pm 0.8$ \\
\hline Lipid, \% & $20.0 \pm 1.1$ & $18.5 \pm 0.7$ & $18.1 \pm 0.9$ & $18.0 \pm 0.9$ & $22.0 \pm 0.1$ & $20.0 \pm 1.0$ \\
\hline $\begin{array}{l}\text { PUFA } \\
\text { C. humicola IE }\end{array}$ & $12.3 \pm 0.6$ & $12.1 \pm 0.6$ & $13.5 \pm 0.7$ & $14.2 \pm 0.5$ & $12.0 \pm 0.4$ & $12.0 \pm 0.9$ \\
\hline Biomass, g/l & $12.5 \pm 0.5$ & $13.5 \pm 0.6$ & $12.1 \pm 0.4$ & $11.5 \pm 0.7$ & $15.0 \pm 0.7$ & $15.4 \pm 0.7$ \\
\hline $\begin{array}{l}\text { PUFA } \\
\text { P. irregulare }\end{array}$ & $5.0 \pm 0.2$ & $5.0 \pm 0.3$ & $5.7 \pm 0.2$ & $6.0 \pm 0.3$ & $5.0 \pm 0.8$ & $5.2 \pm 0.1$ \\
\hline Biomass, g/l & $12.9 \pm 0.2$ & $12.0 \pm 0.6$ & $12.0 \pm 0.6$ & $11.9 \pm 0.3$ & $13.5 \pm 0.7$ & $14.0 \pm 0.7$ \\
\hline Lipid, \% & $20.0 \pm 1.0$ & $19.6 \pm 0.3$ & $19.0 \pm 0.9$ & $19.0 \pm 0.9$ & $21.8 \pm 1.0$ & $20.5 \pm 1.2$ \\
\hline
\end{tabular}




\begin{tabular}{|c|c|c|c|c|c|c|}
\hline & $\mathrm{CO}\left(\mathrm{NH}_{2}\right)_{2}$ & $\mathrm{NaNO}_{3}$ & $\mathrm{NH}_{4} \mathrm{Cl}$ & $\mathrm{NH}_{4} \mathrm{NO}_{3}$ & Peptone & Yeast extract \\
\hline PUFA & $30.1 \pm 1.5$ & $32.5 \pm 1.6$ & $36.1 \pm 1.1$ & $35.2 \pm 1.7$ & $30.4 \pm 1.4$ & $29.9 \pm 1.5$ \\
\hline \multicolumn{7}{|l|}{ Crude oil } \\
\hline \multicolumn{7}{|l|}{ M. globosus 11} \\
\hline Biomass, q/1 & $8.9 \pm 0.5$ & $9.8 \pm 0.4$ & $8.0 \pm 0.4$ & $7.1 \pm 0.3$ & $11.0 \pm 0.5$ & $11.2 \pm 0.1$ \\
\hline Lipid, \% & $39.0 \pm 1.8$ & $37.1 \pm 1.6$ & $36.4 \pm 1.7$ & $36.0 \pm 1.6$ & $40.1 \pm 2.0$ & $39.0 \pm 1.7$ \\
\hline PUFA & $16.0 \pm 0.8$ & $16.0 \pm 0.8$ & $17.8 \pm 0.3$ & $18.5 \pm 0.9$ & $16.0 \pm 0.7$ & $15.8 \pm 0.8$ \\
\hline \multicolumn{7}{|l|}{ C. humicola IE } \\
\hline Biomass, g/1 & $6.3 \pm 0.1$ & $5.9 \pm 0.3$ & $6.0 \pm 0.3$ & $6.1 \pm 0.3$ & $8.0 \pm 0.4$ & $8.6 \pm 0.8$ \\
\hline Lipid, \% & $46.8 \pm 2.3$ & $45.0 \pm 2.6$ & $43.0 \pm 2.1$ & $43.0 \pm 1.9$ & $49.8 \pm 2.5$ & $48.3 \pm 2.3$ \\
\hline PUFA & $24.0 \pm 1.2$ & $23.0 \pm 1.1$ & $26.6 \pm 1.7$ & $27.1 \pm 1.3$ & $25.0 \pm 1.6$ & $25.2 \pm 1.2$ \\
\hline \multicolumn{7}{|l|}{ P. irregulare } \\
\hline Biomass, $\mathrm{q} / 1$ & $7.6 \pm 0.4$ & $7.8 \pm 0.3$ & $7.2 \pm 0.3$ & $7.0 \pm 0.3$ & $9.6 \pm 0.4$ & $9.8 \pm 1.1$ \\
\hline Lipid, \% & $39.0 \pm 1.3$ & $37.8 \pm 1.3$ & $35.0 \pm 1.5$ & $34.8 \pm 1.7$ & $46.1 \pm 1.9$ & $45.0 \pm 2.2$ \\
\hline PUFA & $42.5 \pm 2.1$ & $42.0 \pm 1.8$ & $45.1 \pm 2.2$ & $44.8 \pm 2.1$ & $42.0 \pm 2.1$ & $41.9 \pm 2.1$ \\
\hline
\end{tabular}

Table 4. The amounts of biomass, lipid and poly unsaturated fatty acids in different $C / N$ ratio.

\begin{tabular}{|c|c|c|c|c|c|}
\hline \multirow{2}{*}{ Micromycetes } & \multicolumn{5}{|c|}{ carbon-nitrogen ratio } \\
\hline & 20:1 & $34: 1$ & $50: 1$ & $75: 1$ & $100: 1$ \\
\hline \multicolumn{6}{|l|}{ M. globosus 11} \\
\hline Biomass, g/l & 18.4 & 16.1 & 16.0 & 14.2 & 10.5 \\
\hline Lipid, \% & 18.2 & 19.9 & 23.1 & 20.0 & 20.0 \\
\hline PUFA & 11.0 & 12.0 & 10.8 & 10.0 & 10.0 \\
\hline \multicolumn{6}{|l|}{ C. humicola IE } \\
\hline Biomass, g/l & 17.3 & 15.4 & 15.4 & 15.4 & 15.4 \\
\hline Lipid, \% & 21.8 & 22.1 & 29.8 & 24.1 & 22.0 \\
\hline PUFA & 3.0 & 5.0 & 4.0 & 4.0 & 3.3 \\
\hline \multicolumn{6}{|l|}{ P. irregulare } \\
\hline Biomass, $\mathrm{g} / \mathrm{l}$ & 16.7 & 14.0 & 14.0 & 14.1 & 14.0 \\
\hline Lipid, \% & 20.3 & 20.1 & 22.6 & 20.4 & 20.2 \\
\hline PUFA & 28.1 & 30.1 & 29.3 & 28.2 & 26.1 \\
\hline
\end{tabular}

* All indicators were $\mathrm{P} \leq 0.05$.

Table 5. The impact of changes in the amount of glucose-yeast extract medium on C/N ratio.

\begin{tabular}{llllllll}
\hline № & glucose, \% (w/v) & Yeast extract, \% (w/v) & $\mathbf{C / N}$ & № & glucose, \% (w/v) & Yeast extract, \% (w/v) & C/N \\
\hline 1 & 1 & 0.25 & 16 & 9 & 3 & .25 & 48 \\
2 & 1 & 0.50 & 8 & 10 & 3 & 0.50 & 24 \\
3 & 1 & 0.75 & 5.3 & 11 & 3 & 0.75 & 1.0 \\
4 & 1 & 1.0 & 4 & 12 & 3 & 0.25 & 16 \\
5 & 2 & 0.25 & 32 & 13 & 4 & 0.50 & 64 \\
6 & 2 & 0.50 & 16 & 14 & 4 & 0.75 & 32 \\
7 & 2 & 0.75 & 10.6 & 15 & 4 & 1.0 & 1.4 \\
8 & 2 & 1.0 & 8 & 16 & 4 & & 16 \\
\hline
\end{tabular}

Table 6. The impact of exogenous fat and fatty acids on the amounts of poly unsaturated fatty acids.

\begin{tabular}{|c|c|c|c|c|c|c|}
\hline \multirow{2}{*}{ Micromycetes } & \multicolumn{6}{|c|}{ The amount of PUFA (\%) } \\
\hline & Palmitic acid & Stearic acid & Miristic acid & Flax oil & Cotton oil & control \\
\hline M. globosus 11 & $27.5 \pm 0.9$ & $19.0 \pm 0.8$ & $16.0 \pm 0.6$ & $26.0 \pm 1.2$ & $28.0 \pm 1.3$ & $16.0 \pm 0.8$ \\
\hline C. humicola IE & $29.0 \pm 1.2$ & $25.5 \pm 1.1$ & $25.0 \pm 1.0$ & $31.0 \pm 1.5$ & $31.0 \pm 1.5$ & $25.0 \pm 1.1$ \\
\hline P. irregulare $L X$ & $47.0 \pm 2.1$ & $42.0 \pm 2.0$ & $42.0 \pm 1.9$ & $49.0 \pm 2.4$ & $50.0 \pm 2.4$ & $42.0 \pm 2.0$ \\
\hline
\end{tabular}

Table 7. The different amounts of biomass and lipid in different phosphate concentration.

\begin{tabular}{llllllll}
\hline \multirow{2}{*}{ phosphate concentration } & \multicolumn{2}{l}{ Mucor globosus 11} & \multicolumn{2}{l}{ Cephalosporium humicola IE } & \multicolumn{2}{l}{ Pythium irregulare } \\
\cline { 2 - 7 } & Biomass (g/l) & Lipid (\%) & Biomass (g/l) & Lipid (\%) & Biomass (g/l) & Lipid (\%) \\
\hline 0 (control) & 1.2 & 14.1 & 1.0 & 16.0 & 0.8 & 16.1 \\
$0.5 \mathrm{~g} / 1$ & 7.6 & 20.0 & 5.0 & 12.2 & 5.5 & 22.0 \\
$1.0 \mathrm{~g} / 1$ & 9.0 & 38.0 & 6.3 & 45.3 & 7.5 & 38.0 \\
$2.0 \mathrm{~g} / 1$ & 8.3 & 32.4 & 5.1 & 40.0 & 4.3 & 34.3 \\
$5.0 \mathrm{~g} / 1$ & 5.0 & 25.0 & 5.0 & 35.0 & 4.0 & 31.0 \\
\hline
\end{tabular}


Table 8. The different amounts offatty acids in differentphosphate concentrations.

\begin{tabular}{|c|c|c|c|c|c|c|c|c|c|c|c|c|}
\hline \multirow{4}{*}{ Fatty acids } & \multicolumn{12}{|c|}{ Total amount (\%) } \\
\hline & \multirow{2}{*}{\multicolumn{4}{|c|}{$\begin{array}{l}\text { M. globosus } 11 \\
\text { The amount ofphosphate (\%) }\end{array}$}} & \multicolumn{4}{|c|}{ C. humicola IE } & \multicolumn{4}{|c|}{ P. irregulare $L X$} \\
\hline & & & \multicolumn{10}{|c|}{ The amount ofphosphate (\%) } \\
\hline & 0 (control) & $0.05 \%$ & $0.1 \%$ & $0.5 \%$ & $\mathbf{0}$ & $0.05 \%$ & $0.1 \%$ & $0.5 \%$ & $\mathbf{0}$ & $0.05 \%$ & $0.1 \%$ & $0.5 \%$ \\
\hline Lipid (\%) & 24.0 & 30.0 & 37.0 & 25.5 & 30.0 & 34.0 & 35.0 & 35.0 & 20.0 & 29.5 & 32.0 & 42.5 \\
\hline $\mathrm{C}<14$ & 2.7 & 2.6 & 2.6 & 2.0 & 2.8 & 1.9 & 2.1 & 2.0 & trace & trace & trace & trace \\
\hline C16:0 & 51.0 & 48.0 & 40.0 & 35.0 & 45.0 & 35.0 & 26.0 & 22.0 & 40.0 & 34.5 & 20.3 & 31.7 \\
\hline C16:1 & 9.5 & 9.0 & 8.5 & 8.5 & 8.2 & 7.5 & 7.3 & 7.2 & 5.2 & 5.8 & 5.5 & 5.1 \\
\hline C18:1 & 11.0 & 14.0 & 10.0 & 10.0 & 15.6 & 10.9 & 15.0 & 15.0 & 5.0 & 5.0 & 5.3 & 5.4 \\
\hline C18:2 & 6.0 & 7.3 & 12.0 & 15.2 & 2.0 & 8.0 & 9.0 & 9.9 & 8.1 & 10.0 & 13.4 & 15.3 \\
\hline C18:3 & 8.0 & 9.0 & 13.0 & 15.0 & 5.2 & 13.1 & 16.9 & 18.0 & 8.0 & 10.8 & 12.2 & 14.7 \\
\hline C20:1 & 3.0 & 3.0 & 2.0 & 2.0 & 4.1 & 0 & 0 & 0 & 1.2 & 1.2 & 1.2 & 2.1 \\
\hline C20:3 & 0 & 1.0 & 2.0 & 2.0 & 0 & 3.1 & 3.8 & 3.6 & 5.5 & 5.2 & 10.0 & 11.0 \\
\hline C20:4 & 0 & 0 & 2.0 & 2.4 & 0 & 5.0 & 7.0 & 9.0 & 9.5 & 11.5 & 15.3 & 18.5 \\
\hline C20:5 & 0 & 0 & 2.0 & 2.0 & 0 & 0 & 0 & 0 & 9.8 & 12.5 & 14.5 & 17.7 \\
\hline
\end{tabular}

All indicators were $\mathrm{P} \leq 0.05$.

\section{Discussion}

It is known that the lipid composition of microorganisms had important role in hydrocarbon substrate adopt, because the hydrophobic part of cell increases as a result of lipid accumulation, and this improves the conditions for absorption lipophilic substrates (37).

The study of lipid composition of $C$. humicola IE had special interest which has the ability to synthesize antibiotics cephalosporin because there is no information about synthesis of PUFA in literatures, even about lipogenesis. A high oleaginous and aspirin sensitivity strain of the fungus selected as the research object was identified as Pythium irregulare and called Pythium irregulare $L X$.

Replace of substrate glucose with crude oil had a great impact on lipid fractions. The polar lipids increased from $22.0 \%$ up to $27.0 \%$ in $C$. humicola $I E$ and also from $13.0 \%$ to $39.8 \%$ in $P$. irregulare $L X$; but not a big change in $M$. globosus 11. The maximum biomass accumulated in substrates crude oil in proportion to glucose were equals $28.6 \%$ in C. humicola $I E, 27.2 \%$ in $M$. globosus 11 and $43.6 \%$ in P. irregulare $L X$, respectively. The amount of lipid in dry biomass (\%) was $58.4 \%$ in C. humicola IE, 56.7\% in M. globosus 11 , and $64.1 \%$ $P$. irregulare $L X$, respectively, whereas the amount of lipids was as low as 3- 3.5 times in glucose. The analysis of HPLC demonstrated that the rise the level of lipid in biomass was due to increase the share unsaturated fatty acids (EPA, ARA and GLA) along with reduction of the saturated fatty acids. In $M$. globosus 11 and C. humicola IE, the PUFA were more in the diacylglycerol, triacylglycerol and polar lipids composition, and almost there were not free fatty acids. EPA and ARA were collected at the polar lipids, free fatty acids, and diacylglycerol compositions in $P$. irregulare $L X$. In the triacylglycerol compositions, the level of C20:4, C20:5 acids were too low during growth. In large amounts of C20:4 and C20:5 acids in polar lipids compositions showed important role of them in plastic function of cell membrane.

To some extent there was a difference between the enzymatic activities of fungi, but their activity in accordance with the change in the dynamics of the substrate were almost the same.

The initial $\mathrm{pH}$ to product of maximum amount of GLA was 7.0 in M. globosus 11. In this rate the amount of accumulated biomass was slightly less than $\mathrm{pH} 6.0$, while the amount of lipogenesis and GLA was more $(0.52 \mathrm{~g} / \mathrm{l})$, in addition to 0.21 $\mathrm{g} / 1$ ARA was also synthesized. Initial $\mathrm{pH}$ in C. humicola IE (production of GLA) was 6.0 (0.48 g/l PUFA). In addition to $0.20 \mathrm{~g} / 1$ arachidonic acid was also synthesized. Initial $\mathrm{pH}$ in $P$. irregulare $L X$ (production of GLA and EPA) was 7.0 (1.4 g/l PUFA). Generally, at various $\mathrm{pH}$, the amount of saturated and unsaturated fatty acids decreases with increasing $\mathrm{pH}$ (38- 40). However, some studies have shown that changing in $\mathrm{pH}$ did not affect the composition of lipid and fatty acids $(41,42)$.

Stationary growth phase was very short in all three fungi. The biomass peak of growth curves had been fallen down in a very short period of time. However, reason could have been due to the lack of oxygen or lysis of the biomass. It should be noted that we received the results did not coincide with other published data, several authors try to prove that increasing in growth and lipids occur in below the optimum temperature (43, 44 and 45). However, in our studies, the amount of lipid was significantly higher at $28{ }^{\circ} \mathrm{C}$. Decreasing the cultivation temperature increased the rate of $\mathrm{C} 16: 1$ and $\mathrm{C} 18: 1$ fatty acids of lipid composition in C. humicola IE and M. globosus 11 . The optimal biomass production occurred at $28^{\circ} \mathrm{C}$ at stable temperature, whereas the results of "temperature shifting technique" showed that the greatestproduction of GLA,AT and EPT occurred in at $28^{\circ} \mathrm{C}$ for 5 days followed by at $15^{\circ} \mathrm{C}$ for 2 days.

Increasing amount of inoculum would have increased the biomass. However the problem was caused by lack of $\mathrm{O}_{2}$ because of an increase in viscosity of culture in broth medium. In high inoculum stearic acid and in low inoculum unsaturated fatty acids were synthesized increasingly through changes in the activity of desaturase enzymes which converse saturated fatty acids to unsaturated fatty acids aerobically, therefore their activities are stopped after oxygen consuming $(3,46)$.

Optimal inorganic source of nitrogen was $\mathrm{NaNO}_{3}(0.58 \mathrm{~g} / \mathrm{l}$ PUFA), and organic nitrogen source was peptone $(0.7 \mathrm{~g} / \mathrm{l}$ PUFA) in M. globosus 11. Sources of inorganic nitrogen were 
$\mathrm{NaNO}_{3}\left(0.70 \mathrm{~g} / \mathrm{l}\right.$ PUFA) and $\mathrm{CO}\left(\mathrm{NH}_{2}\right)(0.71 \mathrm{~g} / \mathrm{l}$ PUFA), organic nitrogen source was equally optimal; PUFA yield was about $1.0 \mathrm{~g} / 1$ in $C$. humicola IE (GLA synthesis). Affordable inorganic nitrogen source were $\mathrm{NaNO}_{3}$ and $\mathrm{CO}\left(\mathrm{NH}_{2}\right)(1.1 \mathrm{~g} / 1$ PUFA), as well as source of organic nitrogen was peptone (1.85 g/l PUFA) in P. irregulare $L X$ (GLA, EPA and ARA synthesis). The ratio of carbon and nitrogen has an important role in the fermentation process (47). The highest products of EPA and ARA were in $\mathrm{C} / \mathrm{N}=32(2 \%$ glucose and $0.25 \%$ yeast extract- $20 \mathrm{mg} / \mathrm{g}$ and $15.3 \mathrm{mg} / \mathrm{g}$. The results were similar with the results of Cheng (43).

Chromatography analysis of the fatty acid compositions showed $0.8 \%$ miristic, $22.3 \%$ palmitic, $0.4 \%$ palmitoleic, $2.0 \%$ stearic, $16.7 \%$ oleic, $57.6 \%$ linoleic and $0.3 \%$ linolenic acids in used flax oil, in cotton oil $5.1 \%$ palmitic, $0.5 \%$ palmitoleic, $2.5 \%$ stearic, $18.2 \%$ oleic, $0.5 \%$ eicosane, $15.5 \%$ linoleic and $57.4 \%$ linolenic acids (25\% saturated, $17 \%$ monounsaturated, 58,0\% PUFA. The presented indicators proved that suitable substrate for the synthesis of the fungal PUFA flax oil. It should be noted that, the increase in the quantity of oil was recorded until just rises to $2.0 \%$. There had not been an increase in higher concentrations.

It is associated with activation of acetyl CoA carboxylase, a key enzyme in lipid synthesis (48-50). The maximum amount of lipids biosynthesis was in $2.0 \mathrm{~g} / 1$ of phosphate Phosphorus deficiency in the early days of growth was resulted inincrease in the synthesis of the amount of palmitic acid, decrease in linoleic and linolenic acids and decline in the degree of saturation of lipid in M. globosus 11.However, after some time degree of saturation began to increase gradually. The effect of phosphate concentration was different in the other two fungi. Linolenic acid decreased due to the increase in palmitic acid in C. humicola IE. The phosphoric shortage in lipid of $P$. irregulare $L X$ was resulted in eicosane acids. Phosphorus deficiency also caused decrease eicosane acids in the lipid of $P$. irregulare. In all cases, an increase in saturation degree of SCO was accompanied by a decrease in the polar lipid fraction, especially phospholipids. It should be noted that some researchers insist on the presence of certain phospholipids are obligatory to activity of desaturase system (51- 53).

It was found that the increase in the concentration of crude oil significantly delays the growth of fungi. In addition, the amount of lipids and unsaturation degree of fatty acids increased in biomass. An increase in portion of polar lipids had caused increase in the unsaturation degree; to clarify the fatty acids composition of neutral and polar lipids was analyzed. The amount of oleic and linoleic acids had changed in neutral fraction due to effects of crude oil. Increasing of added oil to medium up to $3.0 \%$ concentration had increased the rate of oleic acid gradually, but decreased at $5.0 \%$ and $10 \%$. One of the most interesting changes was increase in the amount of fatty acids less than $14 \mathrm{C}$. The above-mentioned growth condition, the fatty acids composition and unsaturation of polar lipids degree had been changed more than neutral lipid. The amount of saturated and monounsaturated fatty acids of polar fraction was increased with increasing in crude oil concentration in medium. The amount of short- chain fatty acids was increased up to 5-10 \%. Thus, fatty acids, particularly the mechanisms of elongation and desaturation, play important role in the regulation of permeability of membrane lipids. Because the results showed increase in the proportion of polar lipids to free sterols due to the effect of crude oil in composition of membrane lipids, which this was associated with an increase in proportion of polar lipids in the total lipid fraction. It can be concluded that the process of adaptation of micromycetes to a stressful situation caused by crude oil, induced an increment in the rate of membrane phospholipids with high quantity of unsaturated fatty acids.

\section{Acknowledgments}

This study was funded by the Institute of Microbiology, Azerbaijan National Academy of Sciences (AMEA).

\section{Abbreviations}

\author{
$\mathrm{C} / \mathrm{N}=$ Carbon/ Nitrogen \\ PUFA $=$ Poly unsaturated Fatty Acids \\ $\mathrm{EPA}=$ Eicosapentaenoic Acid \\ GLA $=$ Gamma- Linolenic Acid \\ $\mathrm{ARA}=$ Arachidonic Acid \\ $\mathrm{SCO}=$ Single-Cell Oil \\ HPLC $=$ High-Performance Liquid Chromatography \\ $\mathrm{UV}=$ Ultra Violet \\ $\mathrm{AMEA}=$ Azerbaijan National Academy of Sciences
}

\section{References}

[1] Certik, M., Shimizu, S. (1999). Biosynthesis and regulation of microbial polyunsaturated fatty acid production. J. Bioscience and Bioengineering, 87(1), 1-14.

[2] Jin, M., Huang, H., Xiao A. \& al., e. (2008). A novel two-step fermentation process for improved arachidonic acid production by Mortierella alpine. BiotechnolLett, 30(6), 1087-1091.

[3] Ratledge, C. (2004). Fatty acid biosynthesis in microorganisms being used for single cell oil production. Biochimie, 86 , 807-815.

[4] Armenta, R., Mercia, C. (2013). Single-Cell Oils as a Source of Omega-3 Fatty Acids: An Overview of Recent Advances $J$. Am. Oil Chem. Soc., 90(2), 167-182.

[5] Higashiyama, K., Fujikowa, S., Park, E., Shimizu, S. (2002). Production of arachidonic acid by Mortierella fungi. Biotechnol. Bioproc. Eng., 7, 252-262.

[6] Laoteng, K., Čertík, M., Cheevadhanark S. (2011). Mechanisms controlling lipid accumulation and polyunsaturated fatty acid synthesis in oleaginous fungi. Chemical papers, 65(2), 97-103.

[7] Sijtsma, L., de Swaaf, E. (2004). Biotechnological production and applications of the $\omega-3$ polyunsaturated fatty acid docosahexaenoic acid. Applied Microbiol. Biotechnol., 64(2), 146-153. 
[8] Uemura, H. (2012). Synthesis and production of unsaturated and polyunsaturated fatty acids in yeast: current state and perspectives. Appl. Microbiol. Biotechnol,, 95(1), 1-12.

[9] Kyle, D. (1997). Production and use of single cell oil highly enriched in arachidonic acid. Lipid Technol., 9, 116-121.

[10] Kyle, D. (1996). Production and use of a single cell oil which is highly enriched in docosahexaenoic acid. Lipid Technol., 8, 107-110.

[11] Ratledge, C., Kanagachandran, K., Anderson, A. \& al., e. (2001). Production of docosahexaenoic acid by Crypthecodiniumcohnii grown in a $\mathrm{pH}$-auxostat culture with acetic acid as principal carbon source. Lipids, 36(11), 1241-1246.

[12] Ratledge, C. (2012). Omega-3 biotechnology: errors and omissions. Biotechnol. Adv., 30(6), 1746-1757.

[13] Kennedy, M., Reader, S., Davies, R. (1993). Fatty acid production characteristics of fungi with particular emphasis on gamma linolenic acid production. Biotechnol. Bioengin., 42(5), 625-634.

[14] Bajpai, P., Ward O. (1991). Production of arachidonic acid by Mortierellualpina ATCC 32222. J. Industrial Microbiology. , 8(3), 179-186.

[15] De, B., Kumar, T. (2005). Production and optimization of polyunsaturated fatty acids in some fungi of Aspergillus and Mucor Genus. J. Oil Technol. Assocn. Of India, 37, 8-13.

[16] Fakas, S., Certik, M., Papanikolaou, S. \& al., e. (2008). $\gamma$-linolenic acid production by Cunninghamella growing on complex organic nitrogen sources. Bioresour. Technol. , 99, 5986-5990.

[17] Fakas. S., Galiotoupanayotou. M., Papanikolaou. S. \& al., e. (2007). Compositional shifts in lipid fraction during lipid turnover in Cunninghamellaechinulata. Enzyme Microb. Technol., 1321-1327.

[18] Fakas, S., Papanikolaou, S., Galiotou-Panayotou, M. \& al., e. (2008). Organic nitrogen of tomato waste hydrolysate enhances glucose uptake and lipid accumulation in Cunninghamellaechinulata. J. Appl. Microbiol., 105, 1364-5072.

[19] Papanikolaou, S., Aggelis, G. (2003). Modeling lipid accumulation and degradation in Yarrowialipolytica cultivated on industrial fats. Curr. Microbiol., 46, 398-402.

[20] Papanikolaou, S., Komaitis, M., Aggelis, G. (2004). Single cell oil (SCO) production by Mortierellaisabellina grown on high-sugar content media. Bioresour Technol., 95, 287-291.

[21] Saxena, V., Sharma, C., Bhagat, S. \& al., e. (1998). Lipid and fatty acid biosynthesis by Rhodotorulaminuta. J. Am. Oil Chem. Soc., 75, 501-505.

[22] Shimizu, S., Kawashima, H., Shinmen, Y. \& al., e. (1988). Production of eicosapentaenoic acid by Mortierella fungi. $J$. Am. Oil Chem. Soc., 65, 1455-1459.

[23] Szczesha-Antczak, M., Antczak, T., Piotrowicz-Wasiak, M. \& al., e. (2006) Relationships between lipases and lipids mycelia of two mucor strains. Enzyme Microb. Technol., 39, 1214-1224.

[24] Tao, J., Zhang, X. (2007). Growth low of gamma-inoleic acid production by Cunninghamellaechinulata. J US-China Med Sci, $1, .55-60$.
[25] Andreishcheva, E., Isakova, E., Sidorov. N. \& al., e. (1999). Adaptation to salt stress in a salt-tolerant strain of the yeast Yarrowialipolytica.Biochemistry (Moscow) 64(9), 1259-1266.

[26] Bajpai, P., Bajpai, P. (1992). Arachidonic acid production by microorganisms. Biotechnol. Appl. Biochem., 15(1), 1-10.

[27] Das, T., Huang, Y., Mukerji, P. (2001). D6 Desaturase and $\gamma$ -linolenic acid: a biotechnology perspective, in $\gamma$-Linolenic acid: Recent Advances in Biotechnology and Clinical Applications: AOCS Press, Champaign, IL.

[28] Van der Plaats-Niterink, A. (1981) Monograph of the genus Pythium(Vol. 21): Baarn.

[29] Waterhouse, G. (1968). The genus Pythium. Diagnoses (or descriptions) and figures from the original papers. Mycol Pap., 110, 1-50.

[30] Borkovich, K., Ebbole, D. (2010). Cellular and Molecular Biology of Filamentous Fungi. : ASM Press.

[31] Maheshwari, R. (2005). Fungi: Experimental Methods In: Biology (J. W. Bennett Ed. Vol. 24): Taylor Francis.

[32] Thakur, M., Prapulla, S., Karanth N. (1989). Estimation of intracellular lipids by the measurement of absorbance of yeast cells stained with Sudan Black B. EnzymeMicrob. Technol., 11, 252-254.

[33] Ahmed, S., Singh, S., Pandey A. \& al., e. (2006). Effects of Various Process Parameters on the Production of g-Linolenic Acid in Submerged Fermentation Production of g-Linolenic Acid. Food Technol. Biotechnol., 44(2), 283-287.

[34] Folch, J., Lees, M., Sloane-Stanley, G. (1957). A simple method for the isolation and purification of total lipids from animal tissues. J. Biol. Chem., 226, 497-590.

[35] Bligh, E., Dyer, W. (1978). A rapid method of total lipid extraction and purification. Can. J. Biochem. Physiol., 37(52), 911-917.

[36] PDF. (2008). The Determination of the Iodine Number of Lipids. http://www.drcarman.info/kem220lb/14lab220.

[37] Eroshin, V., Dedyukhina, E., Chistyakova, T. \& al., e. (1996). Arachidonic acid production by species of Mortierella. World $J$. Microbiol. Biotechnol., 12, 91-96.

[38] Mo Xian, J. Y., Y. Kang, J. L. \& al., e. (2001). Production of linolenic acid by Mortierellaisabellina grown on hexadecanol. Letters in Appl. Microbiol., 33(5), 367-370.

[39] Dyal, S., Bouzidi, L., Narine, S. (2005). Maximizing the production of $\gamma$-linolenic acid in Mortierellaramannianavar. ramanniana as a function of $\mathrm{pH}$, temperature and carbon source, nitrogen source, metal ions and oil supplementation. $J$. Food Research International, 38(7), 815-829.

[40] Xia, C., Zhang, W., Zhang, B. (2011). A new cultivation method for microbial oil production: cell pelletization and lipid accumulation by Mucorcircinelloides. Biotechnology for Biofuels, 4(15), 10-15.

[41] Davies, R. (1988). Yeast oil from cheese whey-process development. InSingle Cell Oil (edMoreton ed.): UK: Longman Scientific Technical Press.

[42] Ratledge, C., Bothamp, A. (1977). Pathways of glucose metabolism in Candida 107, a lipid accumulating yeast J. Gen. Microbiol., 102, 391-395. 
[43] Cheng, M., Walker, T., Hulbert, G. \& al., e. (1999). Fungal production of eicosapentaenoic and arachidonic acids from industrial waste streams and crude soybean lipid. Bioresour. Technol., 67(2), 101-110.

[44] O’brien, D., Kurantz, M., Kwoczak, R. (1993). Production of eicosapentaenoic acid by the filamentous fungus Pythiumirregulare Appl. Microbiol. Biotechnol., 40 (2-3), 211-214.

[45] Stredansky, M., Conti, E., Stredanska, S., Zanetti F. (2000). $\gamma$-linolenic acid production with Thamnidiumelegans by solid state fermentation on apple pomace. Biores. Technol., 73, 41-45.

[46] Jenke-Kodama, H., Dittmann, E. (2009). Evolution of metabolic diversity: insights from microbial polyketide synthases Phytochemistry., 70(15-16), 1858-1866.

[47] Ykema, A., Verbree, E., Kater, M. \& al., e. (1988). Optimization of lipid production in the oleaginous yeast Apiotrichumcurvatumin whey permeate. Appl. Microbiol. Biotechnol., 29(2-3), 211-218.

[48] Totani, N., Hyodo, K., Ueda, T. (2000). Minerals essential for growth of the filamentous fungus, Mortierellaalpina. J. Jpn. Oil Chem. Soc., 49(5), 487-493.
[49] Šajbidor, J, Koželouhov, M, Certík, M (1992). Influence of some metal ions on the lipid content and arachidonic acid production by Mortierella sp. Folia Microbiologica, 37, 404-406.

[50] Kyle, D. (1996). Arachidonic acid and methods for the production and use thereof. PCT. Patent WO96/21037.

[51] Russell, N. (1989). Adaptive modifications in membranes of halotolerant and halophilic microorganisms. $J$ Bioenerg. Biomembr., 21, 93-113.

[52] Kates, M., Pugh, E., Ferrante, G. (1984) Regulation of membrane fluidity by lipid desaturases, in Membrane fluidity (M. Kates L. Manson Eds.): Plenum Publ. Corporation, New York.

[53] Jackson, F., Fraser, T., Smith, M. \& al., e. (1998). Biosynthesis of $\mathrm{C} 18$ polyunsaturated fatty acids in microsomal membrane preparations from the filamentous fungus Mucorcircinelloides. European Journal of Biochemistry, 252, 513-519. 